\section{Proof of consent}

Why this matters
Not surprisingly, the ICO urges marketers to up their act in terms of ensuring that they have proof of consent. Clear records should be kept of the date of consent, who obtained it and exactly what information was provided to the person consenting. Marketers should not rely, the ICO states, on a bought-in list unless the seller or broker can provide these details. The Guidance goes further by including an 11-point list of aspects that should be checked by any marketer considering using a third-party list.

The ICO makes it clear that consent to direct marketing cannot be valid if it is given as a condition of subscribing to a service or completing a transaction.

The stricter approaches to, for instance, indirect consent for marketing and time limits on consent will cause concern, particularly as the ICO has not been crystal clear about the extent to which the Guidance is retrospective.

The ICO has stated that the Guidance will not be retrospectively applied before its 9 September 2013 publication date, but what about those millions of email addresses and mobile numbers obtained using consent wording for third-party marketing that now fails the more rigorous ICO test? Will these lists be excused from having to follow the new Guidance? Or, if not, will there be a transitional period allowing marketers time to adapt?

The Direct Marketing Association is raising this and other questions with the ICO and requesting further clarification. In the meantime, all businesses capturing personal data that may be used for future direct marketing (which probably means all businesses) should be urgently reviewing their sign-up mechanisms with a view to making necessary changes.

(The ICO Guidance can be found here: http://www.ico.org.uk/ /media/ documents/library/Privacy_and_electronic/Practical_application/directmarketing-guidance.pdf.)

Stephen Groom, Co-chair - advertising and marketing law group, deputy chair - privacy and data law group, Osborne Clarke

\section{Big changes to Facebook page terms for sweepstakes and contests administration}

\section{Nick Johnson}

Journal of Direct, Data and Digital Marketing Practice (2013) 15, 147-149. doi:10.1057/dddmp.2013.66

Who: Facebook

Where: Menlo Park, California, USA 


\section{What happened}

\section{Why this matters}

When: 27 August 2013

Law stated as at: 9 October 2013

On 27 August 2013, Facebook announced a dramatic relaxation of its previous Pages Terms governing promotions on Facebook. Previously, Facebook's terms required all contests and sweepstakes on Facebook to be administered within apps. Now, promotions can also be run on Page Timelines (but not on Personal Timelines).

This means businesses can now run promotions where the entry route is:

- to post on the business's Facebook Page;

- to like or comment on a post on that Page; or

- to message the Page.

The requirement for each promotion to include a complete release of Facebook by each participant - and an acknowledgement that Facebook doesn't sponsor, endorse or administer it — remains unchanged. Facebook has also clamped down on the practice of asking promotion entrants to 'tag' themselves in content in which they're not actually depicted. This is now expressly prohibited.

The relaxation opens up a range of new possibilities for businesses looking to run promotions on Facebook, and allows for a much quicker and easier route for getting promotions up and running on Facebook. However, the limitations of promotions run on the Page, rather than in an app, need to be understood.

Three key issues stand out:

1. Incorporation of promotion terms: The straightforward entry route may be more marketer-friendly, but it makes it harder to disclose key rules and terms in a way that ensures they are read and agreed to.

2. Data capture: Where a promotion is run within an app, it can be set up in a way that allows the marketer to gather entrant data and use it again — subject to appropriate opt-outs/opt-ins — for marketing purposes. However, that is not possible outside the app environment.

3. Winner contact: If your promotion entry mechanism is submission of a comment against a particular Page post, you may have no guaranteed route for contacting the winner. Unless you already have their contact details, you will have little choice other than to publish their name on the Page and hope that they get in touch.

In light of these limitations, there are probably two main ways in which these new possibilities will be exploited:

- casual and relatively low-value promotions where incorporation and enforceability of the promotion terms is less business-critical; and

- alternatively, promotions with a separate entry form - probably on the brand's own website - and where participation in the promotion requires both completion of the entry form (including signifying 
agreement to promotion terms and usage of personal data) and an action on Facebook.

(The Facebook promotions announcement can be found at: https://www .facebook.com/facebookforbusiness/news/page-promotions-terms.) (The revised Facebook Pages terms can be found here: https://www .facebook.com/page_guidelines.php.)

(New Facebook Promotion Guidelines, including an example that would not previously have been permitted, can be found here: https:// fbcdn-dragon-a.akamaihd.net/hphotos-ak-ash3/ 851577_158705844322839_2031667568_n.pdf.)

Nick Johnson, Partner, advertising and sponsorship law, Osborne Clarke

\section{Did use of YouTube targeting function ensure age gate kept shut?}

\section{Thomas Spanyol}

Journal of Direct, Data and Digital Marketing Practice (2013) 15, 149-151. doi:10.1057/dddmp.2013.67

What happened

How the game was advertised
Who: Advertising Standards Authority, Zenimax Europe Ltd Where: The United Kingdom

When: 18 September 2013

Law stated as at: 3rd October 2013

The Advertising Standards Authority ('ASA') recently ruled on a complaint regarding an online advert for an upcoming computer game. The game in question is called 'The Evil Within' and is in the 'survival horror' genre. This game's target demographic is males aged 18-35 years (see below) and the aim is for the player to help the main character survive in a hostile, gruesome and often post-apocalyptic environment. The game was rated by PEGI, the Europe-wide board that assigns age ratings to interactive entertainment products, with an 18 certificate.

The advert in question took the form of a video advert on YouTube, which was shown to certain targeted users before viewing YouTube videos they had requested. The advert could be skipped after $5 \mathrm{sec}$. This type of advertising is known as a 'skippable pre-roll'. As might be expected from a survival horror game, the advert created a sense of apprehension and was gory. The ASA reported that features included images of 'a person covered in shards of glass', 'a flayed corpse wrapped in barbed wire', 'a bubbling 